\title{
KNOWLEDGE MANAGEMENT SYSTEM IN ETHIOPIAN TEXTILE INDUSTRY
}

\author{
Shemelis Nesibu Wodajeneh \\ Department of Industrial Engineering \\ Wollo University, Kombolcha, Ethiopia
}

ABSTRACT - Knowledge management (KM) is emerging as one of the most powerful management tools in today's manufacturing. It looks at the company resources in order to gain competitive advantage. The management of these resources can mean the difference between success and failure in a competitive environment. This encourages companies to look for better ways in the management of these intangible assets, developing $\mathrm{KM}$ projects in order to provide $\mathrm{KM}$ solutions to solve knowledge bottlenecks through knowledge processes. Firms view knowledge and knowledge management as part of their strategic orientation. Low-cost strategies may emphasize knowledge that can be used to cut costs, lower prices and shorten cycle times whereas differentiation strategies may emphasize knowledge that adds value to a product giving it unique characteristics that serve to differentiate it from the competition. The ability to capture, store and disseminate knowledge within and across organizational boundaries has challenged managers for many years. However, as product lifecycles have decreased and environmental complexity and volatility have increased, the textile industry's need to manage knowledge is intensifying. The main aim of this paper is to shed light on the KM practices in textile manufacturing industries and to design a frame work which will facilitate business model innovation necessary for sustainable competitive advantage in the new business environment characterized by dynamic, discontinuous and radical pace of change. To conduct this study case study is developed to examine how firms manage knowledge internally and externally through relationships with downstream partners across a value-chain within the textile industry. To accomplish the study, semi structured interviews are used to assess the "state of the industry" regarding knowledge management systems. Besides this, to know the attitudes of industrial experts on Knowledge management, a focus group discussion is conducted in some parts of the country. Based on the information gathered from the case research interviews, focus group discussion and the review of the literature, the knowledge management system is developed to solve the companies' problem by keeping its scientific nature and current situation.

Key Terms, Knowledge Management systems, Knowledge Management frame work, Textile Industry

\section{INTRODUCTION}

How does Knowledge Management System help in creating, sharing and using the collective knowledge of its products, processes and people to increase organizational memories of the company? To answer this main question the following sub questions will be answered.

- How does knowledge be captured and stored appropriately for others to access and learn from?

- How does culture of the firm affect the KMS development?

- How does knowledge of the key workers in the firm can be retained and shared in the company?

\section{METHODOLOGY}

After literature review, visual observation of the working system, face to face interview and focus group discussions were conducted with employees of textile industry and industrial experts. The main aim of the survey was to know the current knowledge management practices of textile industry and to get the views of industrial experts on implementation of knowledge management system in textile industry. Based on the findings from visual observation and literature, the problem statement was formulated. Depending on the problem statement, the research question and specific objective of the project was proposed.

Interview 
To know the current practice of the company on managing and using organizational knowledge within the production process, interview was conducted with top management, management of functional departments and front line workers within the company. Furthermore, interview was conducted with different industrial experts to know their attitudes on the importance of implementing knowledge management system in textile industry.

\section{Focus Group Discussion}

In order to test the suitability of the basic survey objectives and comprehensibility of the draft questionnaire a focus group involving different experts with different competence and professional background was established. Besides this the focus group discussion was conducted to get the potential sources of product and process knowledge within the company. According to the study by (mathi, 2004) selecting respondents with the right knowledge about the research area is crucial for qualitative research. The focus group discussion was conducted in the following manner. After selection of appropriate participants, discussion points were distributed one day before the discussion time and on the session a detail discussion was conducted on the importance of development of knowledge management system in textile industry. The output of this discussion is used to strengthen the findings from the company employees using questionnaire

\section{Questionnaire}

Questionnaires were designed to handle the understanding of the term KM and the company's key objective in KM. The Second objective is to handle the aspects that come into play in $\mathrm{KM}$, such as the existence of a strategy, the openness of the culture, the process of quality control of data, the content that is being managed, the function of communities of practice, and the source of knowledge in the company. All these culminate for the final objective to integrate knowledge through each stages of a product life cycle in the company. So the starting point for the questionnaire is a list of practices which can be used in Knowledge Management. Like culture and management, knowledge storing and sharing practice within the organization. 40 questionnaires were collected out of 50 distributed questionnaires. Among the collected questionnaire only 30 of them were filled correctly. Each questionnaire was filled by managements at middle and lower levels, and front line workers of the company.

\section{RESULTS}

In the new five years development and transformation plan, the government of Ethiopia has a strategy to increase the performance and productivity of textile industry in the nation. To be competent in the national and international market in a reliable way, Textile industry has to manage knowledge efficiently. The current practice of the organization on Knowledge Management was collected through questionnaire, interview and visual observation. The purpose of the data collection was to first to handle the understanding of the term Knowledge Management and the company's key objective in Knowledge Management. The second objective was to handle the aspects that come into play in KM, such as the existence of a strategy, the openness of the culture, the functioning of communities of practice, and the source of knowledge in the company. The questionnaire was distributed to company workers who work at top management, middle management and lower management level. Interview questions was concentrated more on lower level workers .Based on the data found from the organization, $83 \%$ of the workers have an understanding about Knowledge Management but they are not practicing on their daily activity and the remaining $17 \%$ of the respondents have not any understanding about Knowledge Management in the organizations.

\section{Potential Sources of Knowledge in Textile Industry}

The organizations have different sources of knowledge from inside and outside of the organization. Respondents were asked to rate sources to create knowledge in their organization and the results of the assessment are shown in the table 1 below.

Table 1. Weighted average for source to create Knowledge in textile industry

\begin{tabular}{|l|l|l|}
\hline S.No. & Source of Knowledge & Weighted Average \\
\hline 1 & External Partner & 3.38 \\
\hline 2 & Company Supplier & 3.57 \\
\hline 3 & Internal Supplier & 4.57 \\
\hline 4 & Company Customer & 4.24 \\
\hline 5 & Workshop & 3.38 \\
\hline 6 & Library & 2.00 \\
\hline 7 & Success Stories & 1.57 \\
\hline
\end{tabular}

As reported by the respondents in the case company, the basic sources to create knowledge in the case company are internal staffs of the company. Besides most of the experts in the focus group discussion also 
said that there are a lot of structured and unstructured knowledge's within the organization with internal staffs but it is not properly managed and used to improve the productivity of the organization. If the organizations use this resource efficiently it will be competent in the national and international markets. All respondents rated company customers at 3,4 and 5 as a source to create knowledge in the textile industry. Experts also said that customers of the organizations can provide different types of knowledge for the organization on the products quality and specifications, but the organizations have not well developed tools that enable them to manage knowledge from their customers. Company suppliers and workshops are also rated as a source of knowledge based on the data collected through questionnaire. Based on the survey results from the focus group discussion, the basic source of knowledge on the types and specification of raw materials are suppliers of the company. But, the companies have not any documented knowledge's of suppliers which will be used for future use. Even if the assessment result of the questionnaire for success stories and library as a source to create knowledge, are lower than the others, experts think library within the Industry as a basic source to create knowledge within the organization, but, the workers of the company have not a good culture of reading and similarly the company does not motivate the employees to develop their reading habit. The basic reason for the respondents for rating success stories lower than the other was that most of the textile industries in Ethiopia have not a well-organized success stories which can be transferred to the employees. But, Kombolcha Textile Industry has success stories in waste management and recycling and the employees have a good knowledge on the benefits of waste management and recycling.

\section{Knowledge Storing Tools}

Even if the organizations have various source of Knowledge, the company has not well organized tools which help the organization to store the available knowledge for future use. To understand the view of the company on potential tools for knowledge storing in the experience of the workers, specialist, information center within the company, Minuet of different discussions, Company newsletter, the company employees are asked to rate based on the existing working environment within and outside of the organization, on a scale of 1 to 5,5 being the most important factor. Results of the questionnaire on the weighted Average shown in the table 2
Table 2. Weighted average for knowledge storing tools

\begin{tabular}{|l|l|l|}
\hline S.No. & $\begin{array}{l}\text { Tools to Store } \\
\text { Knowledge }\end{array}$ & Weighted Average \\
\hline 1 & On minuet & 3.76 \\
\hline 2 & Company newsletter & 1.95 \\
\hline 3 & Information Center & 3.43 \\
\hline 4 & Specialist & 3.29 \\
\hline 5 & Experience & 4.43 \\
\hline
\end{tabular}

Based on the above results of the assessment, experience is the most important tool to store knowledge in textile industry. And company newsletter is ranked as the least important tool to store knowledge. The possible reason for this is that, most of the organizations have not theirs own company newsletter to share different information and knowledge with in it. Experts also agree with the importance of newsletter as a tool for storing knowledge and the company will be benefited from this tool to disseminate the company information uniformly for all company employees.

\section{Knowledge Transferring Tools}

The current environment in the organization on knowledge transfer is accessed using interview and questionnaire. Most of the respondents mentioned some barriers for knowledge transfer in the organizations; Such as Opens of the employees to share their knowledge; Lack of absorption capacity of knowledge receiver; Lack of ICT infrastructure within the organization. Within these variables the employees' rate different types of knowledge transfer tools based on the current practices of the organization as shown below:

Table 3. Weighted average for knowledge transferring tools

\begin{tabular}{|l|l|l|}
\hline S.No. & $\begin{array}{l}\text { Knowledge Transfer } \\
\text { Tools }\end{array}$ & $\begin{array}{l}\text { Weighted } \\
\text { Average }\end{array}$ \\
\hline 1 & On exhibitions & 2.24 \\
\hline 2 & By black board & 2.14 \\
\hline 3 & On employee Journal & 1.86 \\
\hline 4 & Information Center & 2.62 \\
\hline 5 & On meeting & 4.62 \\
\hline
\end{tabular}

Based on the information gathered from different textile industry, meeting is the current basic means for transferring knowledge from source of knowledge to knowledge user. Information center is also use as a knowledge transferring tools, since any employees of the organization can fulfill any shortage of 
information from the center, but the information center has to be equipped with updated information and knowledge. Employees journal is also used as a tool for knowledge transferring within the organization but this tool did not practiced in any of the textile industry .Black board in some textile industry is used for posting daily production schedule for the operator, but it is not common in all organizations. Beyond this the organization can use black board to post knowledge related to the production processes for the company employees.

\section{DISCUSSION}

Knowledge Management Model for Textile Industry Based on the results from the literature review and the data collected from different textile industry, having a model for describing the knowledge management progress is mandatory. The Knowledge management model developed by Muahmed and Hayati 2006 for the banking system has four components, environment, human resources of the bank, Technology and Knowledge Progress. In this model the researcher considered only people within the organization for managing knowledge, but the roles of the customers for knowledge management is vital for effective and efficient management of knowledge, Besides this suppliers of the organization also helps the organization as a source of knowledge to retain it within the organization .So based on the results of this study, the knowledge management model for textile industry has to contains six components ,environment, customers, suppliers, employees, technology and knowledge progress. The proposed model for knowledge management in Ethiopian Textile Industry is as shown in Figure 3.4. The organizational environment forces such as the importance for an organization to maintain its competitive advantage by managing knowledge well or the requirement of the organization to distribute its knowledge among its geographically dispersed human resources may force the organization to initiate a knowledge management programme. Through a combination of customers, suppliers, employees and technology, data and information related to textile products, raw materials and process have to be transformed into knowledge progress and structures that produce products and services. There are mainly three components in the knowledge progress: knowledge creation, knowledge retention and knowledge sharing. Each of these components is discussed below

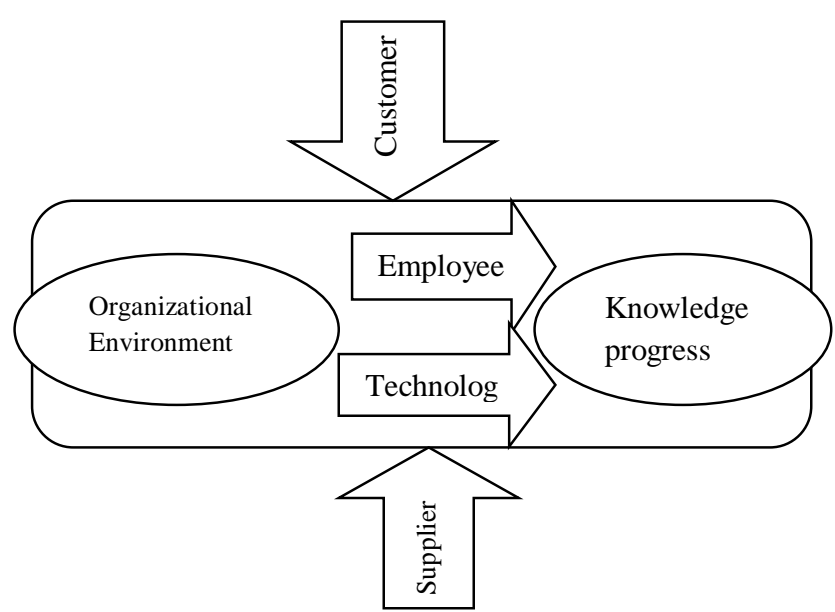

Figure 1.0:-Knowledge Management Model

To implement the proposed knowledge Management Model within the textile manufacturing Industry, customers, suppliers, environment, employees, technology and knowledge progress in each knowledge management process have to be integrated. Besides this to manage knowledge properly, knowledge which can be extracted from company customers and suppliers has to be grouped in to explicit and tacit types. The form proposed in table 4, guides an organization to group the available knowledge into structured and unstructured under each types of knowledge.

Table 4; Forms to Manage Knowledge within the Company

\begin{tabular}{|l|l|l|l|}
\hline & $\begin{array}{l}\text { Source of } \\
\text { Knowledge }\end{array}$ & $\begin{array}{l}\text { Artifacts( } \\
\text { Explicit } \\
\text { type } \\
\text { Knowledge) }\end{array}$ & $\begin{array}{l}\text { Individual } \\
\text { (Tacit types } \\
\text { Knowledge) }\end{array}$ \\
\hline $\begin{array}{l}\text { Structures } \\
\text { Knowledge }\end{array}$ & & $\begin{array}{l}\text { e.g. } \\
\text { Documents }\end{array}$ & \\
\hline $\begin{array}{l}\text { Unstructured } \\
\text { Knowledge }\end{array}$ & & & $\begin{array}{l}\text { e.g. Group } \\
\text { discussion }\end{array}$ \\
\hline
\end{tabular}

The tacit and explicit types of knowledge can be captured from within and outside of the organization, but the organization has to be learned before, during and after using the available knowledge effectively and efficiently. 


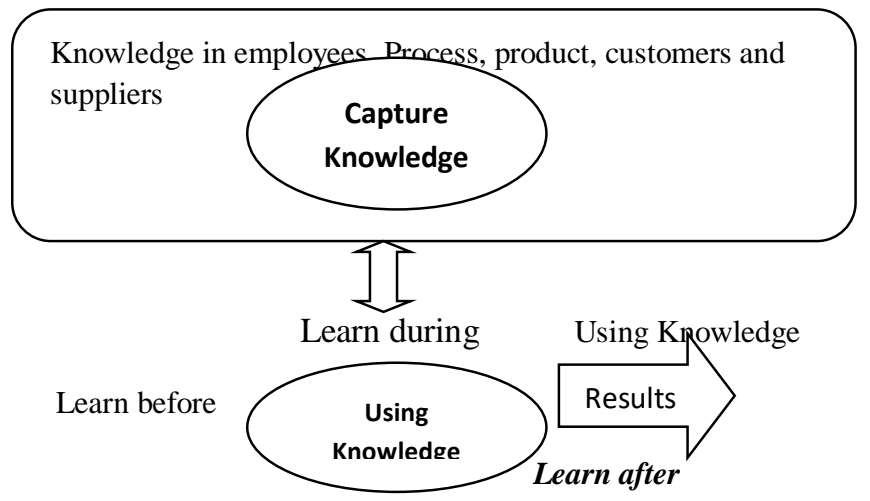

Figure 1.2. Framework for Knowledge Management Environment

In any work environment most jobs are inaccurate: best decisions depend on situation and available knowledge, which drive the need to rethink current approaches to problem solving and decision-making. Time pressure demands that organizations capitalize on lessons learned. However, this approach has many limitations as the decisions made based on past experience may not be the most appropriate one. Consequently, there is a need for a sophisticated level of "know-how", "know-what", "know-who", "knowwhere" and "know-why". Organizations need to have high performance to respond to market demands such as the right product at the right time, customer focused service and marketing strategies, high performance organizational practices and access to high value of information and knowledge. A high performance organization pursues its goals in a changing environment by adapting and enhancing its behavior according to what it knows about itself and the world in which it needs to succeed. It is therefore a learning organization that is skilled at creating, acquiring, organizing and sharing knowledge that can gain competitive advantage. The major components influencing the success of organization in adopting knowledge management are employees of the company and technology within the company, and customers and suppliers outside of the company.

\section{Employees of the company}

Based on the results of this study, a challenge for knowledge management is managing and training people to embrace a knowledge management oriented culture. According to Duffy (2005), sharing knowledge especially tacit type knowledge or individual knowledge could result in power redistribution and face cultural resistance. Many studies emphasized the importance of corporate culture in successful knowledge management (Earl \& Scott, 2005; Havens \& Knapp, 2005). Some even claim that knowledge management can be successful only with a change in culture. Furthermore, the new culture must be integrated with existing business processes and practices. Communication, reward systems, and leadership are important cultural factors in implementing knowledge management. The leadership has to motivate the employees of the company to have a good understanding about knowledge, Knowledge management and Knowledge management system

\section{Technology}

Based on the findings from the literature and assessments, several types of technological tools are necessary to allow knowledge sharing anytime and anywhere. Mobile technology, local area networks, email, internet and intranets are some of the commonly used technologies for knowledge creation and sharing. Knowledge repositories and data warehouse are some of the technologies used for data retention. But currently, these technological tools are not effectively practiced and implemented. Even in some of the textile industry, they have not any of these mentioned technological tools. To retain and use organizational knowledge, textile industry has to implement and use technological tools in their working system.

\section{Customers}

Customer knowledge is a main asset for all businesses. It is the basis of most improvements in customer values. (Rowly, 2002) with stress on knowledge as a major competitive factor in the global economy, corporation may be overlooking a key element: customer knowledge. So this Customer knowledge can play a great role in Knowledge management model in textile industry. The types of this knowledge can be: Knowledge for customer: The knowledge that the customers can gain in order to satisfy their knowledge needs. It can include product, market, and supplier knowledge. It can be sourced from our company or from other external sources like other customers and competitors.

Knowledge about customer: The kind of knowledge that enables the company to know the customer better, to understand their motivations, and to address them better. Includes requirements, expectations, and purchasing activities.

Knowledge from customer: The kind of knowledge that deals with products, suppliers, and markets. It can be used to improve the company products and services 


\section{Knowledge Progress}

As per the developed knowledge management model, Knowledge progress can be divided into three components namely knowledge creation, knowledge retention and knowledge sharing. The detail analyses of these components with the required tools are discussed below:

\section{Knowledge generation/creation process}

Knowledge generation requires tools that enable the acquisition, synthesis, and creation of knowledge. Based on the data collected from the case company and literature review, the following tools listed in Table below support the knowledge generation process from various sources of knowledge for the organizations. Besides this the cultural factors which are relevant to $\mathrm{KM}$ are listed in with the required tools. Each cultural factor has a great effect on generation of knowledge in the company. The sample format for this process is shown in the table 5 below Table 5.Form used to generate/create Knowledge within the organization

\begin{tabular}{|c|c|c|c|c|c|c|}
\hline \multirow{2}{*}{$\begin{array}{l}\text { Source to } \\
\text { Generate } \\
\text { Knowledge }\end{array}$} & \multicolumn{2}{|c|}{$\begin{array}{l}\text { Types of } \\
\text { Knowledge }\end{array}$} & \multicolumn{4}{|c|}{$\begin{array}{l}\text { Cultural Factors relevant to Knowledge } \\
\text { Management }\end{array}$} \\
\hline & $\begin{array}{l}\text { Explic } \\
\text { it } \\
\text { types }\end{array}$ & $\begin{array}{l}\text { Taci } \\
t \\
\text { Type }\end{array}$ & $\begin{array}{l}\text { Willingn } \\
\text { ess to } \\
\text { learn }\end{array}$ & $\begin{array}{l}\text { Open } \\
\text { ness }\end{array}$ & $\begin{array}{l}\text { Trus } \\
t\end{array}$ & $\begin{array}{l}\text { Self- } \\
\text { Responsib } \\
\text { ility }\end{array}$ \\
\hline $\begin{array}{l}\text { Best } \\
\text { Practice }\end{array}$ & & & & & & \\
\hline $\begin{array}{l}\text { Brainstormi } \\
n g\end{array}$ & & & & & & \\
\hline $\begin{array}{l}\text { External } \\
\text { partners }\end{array}$ & & & & & & \\
\hline $\begin{array}{l}\text { Internal } \\
\text { Staffs }\end{array}$ & & & & & & \\
\hline Exhibition & & & & & & \\
\hline $\begin{array}{l}\text { Knowledge } \\
\text { Circles }\end{array}$ & & & & & & \\
\hline Workshops & & & & & & \\
\hline Library & & & & & & \\
\hline Competitors & & & & & & \\
\hline
\end{tabular}

\section{Knowledge storing/retention models}

The textile product Manufacturing Industry has to classify the filtered knowledge from different sources in to tacit and explicit type and add it to the memory of the organization. The stored knowledge in manuals, databases, case studies, reports and even corporate processes and makes up one column of the core activities (Explicit type knowledge). The other columns consist of the knowledge stored in the brains of thousands of employees who leave their respective organizations at the end of each working day (Implicit type knowledge). The frame work for storing knowledge for textile product manufacturing Industry is shown in table 6 below:
Table 6: Forms for Storing Knowledge

\begin{tabular}{|c|c|c|c|c|c|c|}
\hline \multicolumn{4}{|c|}{ Explicit Types of Knowledge } & \multicolumn{3}{|c|}{ Tacit types Knowledge } \\
\hline $\begin{array}{l}\text { Stored } \\
\text { Knowl } \\
\text { edge in } \\
\text { Manual } \\
\text { s }\end{array}$ & $\begin{array}{l}\text { Stored } \\
\text { Knowle } \\
\text { dge in } \\
\text { reports }\end{array}$ & $\begin{array}{l}\text { Stored } \\
\text { Knowle } \\
\text { dge in } \\
\text { Corpor } \\
\text { ate } \\
\text { Process }\end{array}$ & $\begin{array}{l}\text { Stored } \\
\text { Knowle } \\
\text { dge in } \\
\text { database }\end{array}$ & $\begin{array}{l}\text { Knowledge } \\
\text { stored in the } \\
\text { brain of } \\
\text { experts }\end{array}$ & $\begin{array}{l}\text { Knowledge } \\
\text { stored in the } \\
\text { brain of } \\
\text { technical } \\
\text { assistance }\end{array}$ & $\begin{array}{l}\text { Captur } \\
\text { ed } \\
\text { from } \\
\text { other s }\end{array}$ \\
\hline & & & & & & \\
\hline & & & & & & \\
\hline
\end{tabular}

The manager of the textile product manufacturing Industry has to motivate all the concerned departments within the company to use and implement the knowledge storing format in their day to day activities. Besides all the stated sources of knowledge, the industry has to look for others important knowledge from within and out of the industry and store it using the developed format.

\section{Knowledge sharing models}

Based on the collected data from case company and literature review, the manufacturing Industry has to disseminate the sored knowledge within the industry to employees who are working at different levels of the company. Along with this the Industry can also extract the useful knowledge from different sources. The framework in table 7 is developed for textile product manufacturing Industry for sharing knowledge to the company employees.

Table 7: Forms for Knowledge sharing

\begin{tabular}{|l|l|l|l|l|l|l|}
\hline $\begin{array}{l}\text { Tools to } \\
\text { transfer } \\
\text { Knowledg } \\
e\end{array}$ & $\begin{array}{l}\text { Types of } \\
\text { Knowledge }\end{array}$ & \multicolumn{2}{|c|}{$\begin{array}{l}\text { Cultural Factors relevant to } \\
\text { Management }\end{array}$} \\
\cline { 2 - 7 } & $\begin{array}{l}\text { Explic } \\
\text { it } \\
\text { types }\end{array}$ & $\begin{array}{l}\text { Tacit } \\
\text { Type } \\
\text { s }\end{array}$ & $\begin{array}{l}\text { Willingne } \\
\text { ss to learn }\end{array}$ & $\begin{array}{l}\text { Opennes } \\
\text { s }\end{array}$ & Trust & $\begin{array}{l}\text { Self- } \\
\text { Responsi } \\
\text { bility }\end{array}$ \\
\hline $\begin{array}{l}\text { Exhibitio } \\
n\end{array}$ & & & & & & \\
\hline $\begin{array}{l}\text { Informati } \\
\text { on center }\end{array}$ & & & & & & \\
\hline $\begin{array}{l}\text { Notice } \\
\text { board }\end{array}$ & & & & & & \\
\hline $\begin{array}{l}\text { Internal } \\
\text { Knowledg } \\
\text { e Markets }\end{array}$ & & & & & & \\
\hline $\begin{array}{l}\text { Telegram } \\
\text { Groups }\end{array}$ & & & & & & \\
\hline $\begin{array}{l}\text { Employee } \\
\text { Journal }\end{array}$ & & & & & & \\
\hline $\begin{array}{l}\text { Social } \\
\text { Media }\end{array}$ & & & & & & \\
\hline E-mails & & & & & & \\
\hline Meeting & & & & & & \\
\hline
\end{tabular}


Principles for Knowledge-Sharing.

To implement this knowledge sharing tools the manufacturing industry has to have its own principles within the industry. Some of the principles which should be practiced within the industry are ; building up good relationships on personal contact and trust; create a sharing knowledge base by vocational training, joint discussion, publication, team building and job rotation; provide adequate meeting places and time for exchanging ideas; Establish incentives for those who share their knowledge; offer capacity building to employees in order to become more creative; appreciate idea irrespective of the status of the person who provide it( non-hierarchical handling ideas) and Encourage employees to admit knowledge gaps and project failures; do not blame such honesty.

\section{CONCLUSION}

As the root of value creation increasingly depends on leveraging firms' intangible assets, Knowledge Management Systems (KMS) are emerging as powerful sources of competitive advantage. However, the general appreciation of the importance of such systems seems to be accompanied by implementing the required tools for knowledge management process in a system within adequate consideration of the fundamental knowledge problems that the KMS are likely to solve. This research contributes to the stream of a research on Knowledge Management System by proposing an appropriate tools for creating, storing and sharing with in textile industry to make the organization competent in the national and international market. The long term effects of the use of KMS provide a window into work in a number of reference disciplines that would enrich the utility of Knowledge management system and also open up fruitful areas for future research.

\section{RECOMMENDATION}

Based on this study the following points are recommended.

- Managing organizational knowledge makes the company competent in both the national and international market. So the organization has to implement this research to retain and use knowledge with in the organizations.

- Textile industry is losing a great deal of institutional knowledge and the need to invest more time and the necessity to have a targeted implementation of Knowledge Management and achieving it within the next production years. Moreover, Knowledge Management is not just about systems, it is about people and institutional attitudes. The staff here should undergo reorganization and learn to share or participate constructively in Knowledge transfer between those who were given new tasks and those who had done the tasks before. There are, and still will be employees who do not have a solid grasp on their duties on knowledge transfers or knowledge sharing. As a result many employees are people- who are slow to change, and resistant to sharing their knowledge. Many fear others taking over their task and fear job security. The key is and will be to convince them that they are more necessary to the firm as a regular-normal employee and as a knowledge expert. Some trendsetterers embrace change and thus help other employees in utilizing their enthusiasm to drive KM projects implementation forward.

- To facilitate the implementation of knowledge management system with in different production process, the company has to adopt diverse technologies to automate the system wit in the company starting from simple technologies like e-mail system to expert system and Enterprise Resource Planning packages (ERP). Especially ERP enables the company to capture, retain and share organizational knowledge found in different functions wit in the company.

\section{ACKNOWLEDGEMENT}

The completion of this study could not have been possible without the active support of My Family and Friends. I would also thank the Staffs of Kombolcha Textile Share Company for their kind support by providing all the required information at every stage of my research work. Their prompt inspirations, timely suggestions with kindness, enthusiasm and dynamism have enabled me to complete this research. I thank profusely all the staffs of Kombolcha Institute of Technology for their kind help and cooperation throughout our study period.

\section{REFRENCES}

1 Begon, C. ((2010)). Alignment of Knowledge Management Strategy in Practice.In :T.Eduardo (Ed) Developments of Knowledge Management system:. Proceedings of the 11th European Conference on Knowledge Management. Portugal.

2 Epistemic. (2010). Information on www.epistemics.Co.UK|Notes|63-0-0.htm. 


\section{International Journal of Engineering Applied Sciences and Technology, 2020 Vol. 5, Issue 2, ISSN No. 2455-2143, Pages 631-638 \\ Published Online June 2020 in IJEAST (http://www.ijeast.com)}

Knowledge Acquisition (online). Retrieved from

3 Brian N. and Kurt W. (2006). A Knowledge Management Theory Papers,.

4 Hafizi Muhamad Ali, a. H. (2006). Knowledge management in Malaysian banks: a new paradigm. . Journal of Knowledge Management Practice, Vol. 7, No. 3.

5 G., M. R. ((2005).). Knowledge Management as Competitive Advantage in the Textile and Apparel Value Chain, National Textile Center Annual Report.

6 Lumes, M. (2005). Environmental regulation and economic competitiveness: Evidence from the textile industry. Vietnam: www.lumes.lu.se/database.

7 Evily, D., \& Chakravarthy, S. (2002). The persistence of knowledge-based advantage: an empirical test for product performance and technological knowledge. Strategic Management Journal, Vol.23 No.4, pp 285-305.

8 Horwitch, M. a. (2002). Helping knowledge management be all it can be, Journal of Business Strategy, Vol. 23 No. 3,, pp. 26-32.

9 Holm, J. (2001). Capturing the spirit of knowledge management. Paper presented at the American Conference on Information Systems, Boston.

10 Magnani, D. ((2001).). How to Create Business Value with Knowledge Management Solutions That Work". In: Jones, R. (Ed.), Captured Knowledge. Presentations and Notes of the Fifth KM World Conference and Exposition, Information Today. Medford, New Jers.

11 Gupta, B. I. (2000). Knowledge management: practices and challenges,. Industrial Management \& Data Systems, Vol. 100 No. 1, 17-21.

12 Hansen, M. N. ((1999).). What's your strategy for managing knowledge? Harvard Business Review, Vol.77, No.2,, pp 106-116.

13 Anthes, G. ((1998)). Learning How to Share. Computerworld, Vol. 32, No. 8,, pp. 75-77.

14 Cohen, W. L. ((1990).). Absorptive Capacity: A New Perspective on Learning and Innovation. . Administrative Science Quarterly, Vol.35, No.1, pp 128-152.

15 Gottschalk, P. (1950). Strategic Knowledge Management Technology: T.Jan, P.K. Mehdi and W.Ingrid(Eds),. Idea Group Publishing 